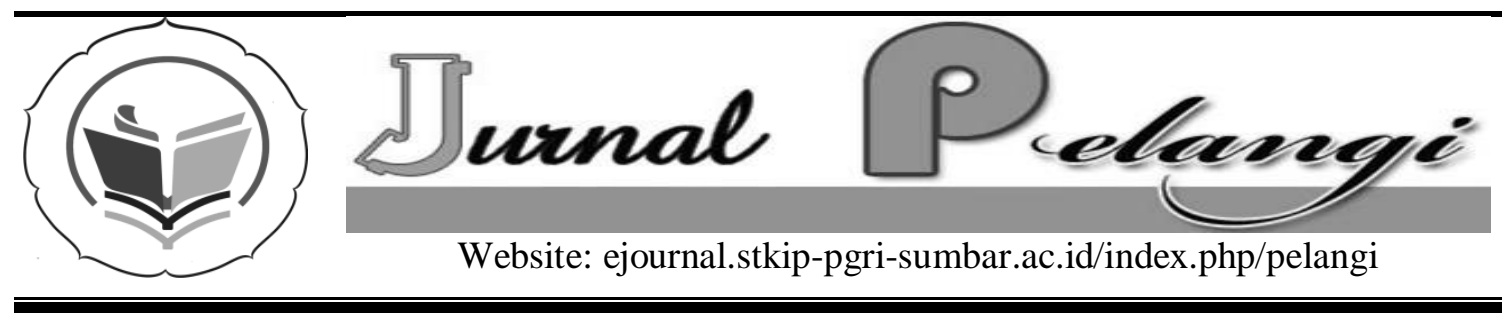

\title{
IMPLEMENTASI PEMBELAJARAN AKTIF TIPE SNOWBALL THROWING DISERTAI PENGGUNAAN PETA KONSEP UNTUK MELIHAT KEAKTIFAN SISWA
}

\author{
Werry Febrianti \\ Institut Teknologi Sumatera \\ werry.febrianti@itera.ac.id
}

\begin{tabular}{|c|c|}
\hline INFO ARTIKEL & Abstrak \\
\hline $\begin{array}{l}\text { Diterima: } \\
8 \text { Mei } 2017 \\
\text { Direview: } \\
8 \text { Mei } 2017 \\
\text { Disetujui: } \\
\text { 10 September } 2017\end{array}$ & \multirow{3}{*}{$\begin{array}{l}\text { Pembelajaran yang mengaktifkan siswa untuk bertanya, } \\
\text { diskusi, serta kerja sama sangat diperlukan oleh siswa SMP } \\
\text { kelas VIII. Pembelajaran yang menyenangkan dengan } \\
\text { menggunakan metode belajar dengan bermain bisa diterapkan } \\
\text { dalam pembelajaran matematika yaitu dengan implementasi } \\
\text { pembelajaran aktif tipe snowball throwing yang disertai } \\
\text { penggunaan peta konsep. Implementasi pembelajaran ini bisa } \\
\text { meningkatkan aktivitas siswa di dalam belajar karena adanya } \\
\text { aktivitas snowball throwing yang disertai penggunaan peta } \\
\text { konsep. }\end{array}$} \\
\hline Kata Kunci: & \\
\hline \multirow{2}{*}{$\begin{array}{l}\text { Pembelajaran Aktif, } \\
\text { Snowball Throwing, } \\
\text { Peta Konsep, Aktivitas } \\
\text { Siswa }\end{array}$} & \\
\hline & Abstract \\
\hline Keywords: & $\begin{array}{l}\text { Students in 8-grade Junior High School need to be active for } \\
\text { asking questions, discussions and also in team work. Learning }\end{array}$ \\
\hline $\begin{array}{l}\text { Active Learning, } \\
\text { Snowball Throwing, } \\
\text { Concept Map, } \\
\text { Students's Activity }\end{array}$ & $\begin{array}{l}\text { a lesson in happy situation by using active learning type like } \\
\text { snowball throwing with concept map. This active learning can } \\
\text { increase the activity of the students in learning process } \\
\text { because there are activities that implemented snowball } \\
\text { throwing with concept map to understand the lesson that they } \\
\text { learn. }\end{array}$ \\
\hline
\end{tabular}

\section{PENDAHULUAN}

Matematika merupakan pelajaran yang bersifat abstrak. Oleh sebab itu, dibutuhkan strategi dalam pengajaran matematika sehingga siswa dapat memahami dan mengingat tentang apa yang dipelajarinya. Suatu konsep akan lebih mudah diingat oleh siswa bila konsep tersebut disajikan melalui prosedur dan langkah-langkah yang tepat, jelas, dan menarik.

Tak ada proses belajar tanpa keaktifan siswa karena pada dasarnya belajar adalah perbuatan, belajar hanya mungkin terjadi apabila siswa tersebut aktif dan mengalami sendiri. Siswa dituntut untuk selalu aktif agar dapat mencapai pembelajaran yang optimal 
dan juga efektif. Dengan siswa aktif bertanya, mengemukakan ide-ide, banyak berlatih mengerjakan soal-soal matematika dapat mempermudah siswa menerima materi yang diajarkan.

Gagne dalam Agus Suprijono (2010:2) mengatakan bahwa belajar adalah perubahan disposisi atau kemampuan yang dicapai oleh seseorang melalui aktivitas. Perubahan disposi tersebut tidak diperoleh langsung dari pertumbuhan secara alamiah. Dimyati dan Mudjiono (2002:3) menyatakan bahwa pembelajaran adalah kegiatan guru secara terpogram dalam desain instruksional untuk membuat siswa belajar secara aktif.

Silberman (2009:xxvi) mengungkapkan cara-cara yang dapat dilakukan dalam pembelajaran aktif agar siswa lebih aktif sejak awal yaitu : pembentukan tim, penilaian di tempat, pelibatan belajar secara langsung.

Permasalahan yang dijumpai pada kelas VIII SMPN 1 Padang berdasarkan hasil observasi adalah proses pembelajaran berlangsung secara monoton sehingga menimbulkan kebosanan siswa untuk mempelajari matematika. Hal ini juga ditunjang dengan tidak adanya proses mencari, menemukan, mempelajari sendiri tentang materi yang dipelajari. Oleh karena itu, diimplementasikanlah pembelajaran aktif tipe Snowball Throwing yang disertai penggunaan peta konsep dalam pembelajaran matematika yang diterapkan pada kelas VIII SMP Negeri 1 Padang untuk melihat peningkatan aktivitas siswa dalam proses pembelajaran.

\section{METODE PENELITIAN}

Penelitian ini menggunakan pembelajaran aktif tipe Snowball Throwing yang disertai penggunaan peta konsep untuk melihat peningkatan aktivitas siswa. Snowball Throwing merupakan salah satu model pembelajaran aktif yang banyak melibatkan siswa. Peran guru di sini hanya sebagai pemberi arahan awal mengenai topik yang akan dipelajari dan selanjutnya penertiban terhadap jalannya proses pembelajaran.

Dalam model pembelajaran Snowball Throwing, bola salju merupakan kertas yang berisikan pertanyaan yang dibuat oleh siswa kemudian dilempar kepada temannya sendiri untuk dijawab. Dalam model pembelajaran ini, guru membentuk kelompok yang diwakili oleh ketua kelompok untuk mendapat tugas dari guru untuk menjelaskan materi kepada teman-temannya dalam satu kelompok kemudian masing-masing siswa tersebut membuat pertanyaan yang dibentuk seperti bola (kertas pertanyaan) lalu dilempar ke siswa lain yang masingmasing siswa menjawab pertanyaan dari bola yang diperoleh.

Apabila siswa mampu menguasai materi yang dijelaskan ketua kelompok dengan menggunakan bantuan peta konsep maka siswa dapat membuat pertanyaan yang berkualitas yang dapat meningkatkan kemampuan berpikir kritis siswa dalam membuat dan menjawab pertanyaan sehingga dapat menunjang siswa untuk menguasai dan memahami materi pelajaran tersebut.

Agus Suprijono (2010: 128) mengungkapkan langkah-langkah penerapan model belajar Snowball Throwing sebagai berikut: guru menyampaikan materi yang akan disajikan, serta membentuk kelompokkelompok dan memanggil masingmasing ketua kelompok untuk memberikan penjelasan tentang materi. Kemudian, masing-masing ketua kelompok kembali ke kelompoknya masing-masing untuk menjelaskan materi yang telah disampaikan oleh guru kepada teman-teman di kelompoknya. 
Selanjutnya, masing-masing siswa diberikan satu lembar kertas kerja untuk menuliskan satu pertanyaan apa saja yang menyangkut materi yang sudah dijelaskan oleh ketua kelompok. Kemudian kertas yang berisi pertanyaan tersebut dibuat seperti bola dan dilempar dari satu siswa ke siswa yang lain selama \pm 15 menit. Setelah siswa dapat satu bola/satu pertanyaan, diberikan kesempatan kepada siswa untuk menjawab pertanyaan yang tertulis dalam kertas berbentuk bola tersebut secara bergantian.

Snowball Throwing adalah salah satu model pembelajaran aktif yang dapat meningkatkan peran siswa di dalam proses pembelajaran. Hal ini terlihat pada langkah-langkah penerapan model belajar Snowball Throwing oleh Agus Suprijono di atas terdapat pengajaran yang dilakukan oleh ketua kelompok kepada teman-teman di kelompoknya atau dapat dikatakan bahwa terjadi tutor sebaya untuk memahami materi yang sedang mereka pelajari. Aktivitas lainnya adalah membuat dan menjawab soal serta melakukan permainan antar kelompok sehingga dapat menghilangkan kebosanan siswa di dalam belajar. Hal ini dapat meningkatkan antusias siswa dalam belajar matematika.

Instrumen yang digunakan dalam penelitian ini adalah lembar observasi. Lembar observasi merupakan lembaran yang dirancang untuk melihat aktivitas siswa selama proses pembelajaran berlangsung. Langkah-langkah yang digunakan dalam menyusun lembar observasi adalah menentukan indikatorindikator aktivitas yang akan diamati, merancang lembar observasi, memvalidasi lembar observasi kepada satu orang dosen jurusan matematika FMIPA UNP dan dua orang guru matematika yang mengajar di kelas VIII SMP Negeri 1 Padang.
Pengamatan melalui aktivitas siswa dilakukan oleh observer dengan mencatat dan mendaftarkan banyak siswa yang melakukan aktivitas yang diamati. Siswa yang melakukan aktivitas yang sama lebih dari satu kali hanya dihitung satu saja untuk setiap kali pertemuan.

\section{HASIL DAN PEMBAHASAN}

Dari data yang diperoleh melalui lembar observasi, dihitung persentase aktivitas belajar siswa dalam setiap kali pertemuan. Persentase aktivitas dihitung dengan rumus yang dikemukakan oleh Nana (2009: 130) yaitu:

$$
P=\frac{F}{N} \times 100 \%
$$

Keterangan

$P$ : Persentase siswa yang melakukan aktivitas pada indikator tertentu

$F$ : Frekuensi siswa yang melakukan aktivitas pada indikator tertentu

$N$ : Jumlah siswa

Setelah diperoleh persentase aktivitas siswa, kemudian dilihat kriteria aktivitas seperti yang dikemukakan oleh Dimyati dan Mudijono (2002: 125) yaitu:

Tabel 1. Kriteria Penilaian Aktivitas Siswa

\begin{tabular}{ll}
\hline \multicolumn{1}{c}{ Persentase } & \multicolumn{1}{c}{ Kriteria } \\
\hline $0 \% \leq P<25 \%$ & Sedikit sekali \\
\hline $25 \% \leq P<50 \%$ & Sedikit \\
\hline $50 \% \leq P<75 \%$ & Banyak \\
\hline $75 \% \leq P \leq 100 \%$ & Banyak sekali \\
\hline
\end{tabular}

Pengamatan aktivitas siswa dilakukan pada setiap pertemuan oleh dua orang observer yaitu satu orang guru matematika yang mengajar di kelas eksperimen dan satu orang mahasiswa matematika. Data aktivitas siswa diolah dengan perhitungan persentase skor penilaian setiap pertemuan untuk setiap indikator. Data hasil observasi siswa setiap pertemuan selama proses 
pembelajaran menggunakan pembelajaran aktif tipe Snowball Throwing yang disertai penggunaan peta konsep dapat dilihat pada Tabel 2.

Berdasarkan Tabel 2 terlihat bahwa persentase aktivitas siswa selama pembelajaran matematika dengan menggunakan model pembelajaran aktif tipe Snowball Throwing yang disertai dengan penggunaan peta konsep untuk setiap pertemuan mengalami peningkatan. Aktivitas yang paling banyak dilakukan adalah melakukan diskusi dengan anggota kelompok untuk memahami materi yang sedang dipelajari yang berkisar antara 86,36 - $100 \%$ dan aktivitas yang lebih rendah persentasenya dari semua indikator aktivitas siswa adalah membuat atau melengkapi catatan sendiri yang berkisar antara 81,82-82,61\%.

Berdasarkan Tabel 2 terlihat bahwa aktivitas yang dilakukan siswa pada setiap pertemuan cenderung meningkat. Aktivitas siswa untuk setiap indikator pada pertemuan pertama termasuk pada kriteria banyak sekali kecuali pada aktivitas 3 yang termasuk pada kriteria banyak. Aktivitas siswa pada pertemuan kedua termasuk pada kriteria sedikit dan banyak sekali. Aktivitas siswa pada pertemuan ketiga dan keempat termasuk pada kriteria banyak sekali. Aktivitas siswa pada pertemuan kelima juga termasuk pada kriteria banyak sekali dan banyak kecuali pada aktivitas 3 yang tergolong pada kriteria sedikit. Aktivitas siswa pada pertemuan keenam termasuk pada kriteria banyak sekali.

Tabel 2. Jumlah dan Presentase Siswa yang Melakukan Aktivitas Belajar Selama Penerapan Model Pembelajaran Aktif Tipe Snowball Throwing yang Disertai Penggunaan Peta Konsep

\begin{tabular}{|c|c|c|c|c|c|c|c|c|c|c|c|c|}
\hline \multirow{3}{*}{$\begin{array}{l}\text { Aktivitas } \\
\text { Siswa }\end{array}$} & \multicolumn{12}{|c|}{ Pertemuan Ke- } \\
\hline & \multicolumn{2}{|r|}{$\mathrm{I}$} & \multicolumn{2}{|r|}{ II } & \multicolumn{2}{|c|}{ III } & \multicolumn{2}{|r|}{ IV } & \multicolumn{2}{|c|}{$\mathrm{V}$} & \multicolumn{2}{|r|}{ VI } \\
\hline & $\mathrm{F}$ & $\%$ & $\mathrm{~F}$ & $\%$ & $\mathrm{~F}$ & $\%$ & F & $\%$ & $\mathrm{~F}$ & $\%$ & $\mathrm{~F}$ & $\%$ \\
\hline 1 & 19 & 86,36 & 20 & 95,24 & 22 & 100 & 23 & 100 & 23 & 100 & 23 & 100 \\
\hline 2 & 19 & 86,36 & 8 & 38,09 & 20 & 90,91 & 22 & 95,65 & 23 & 100 & 23 & 100 \\
\hline 3 & 16 & 72,73 & 8 & 38,09 & 22 & 100 & 22 & 95,65 & 10 & 43,47 & 22 & 95,65 \\
\hline 4 & 20 & 90,91 & 9 & 42,86 & 21 & 95,45 & 23 & 100 & 20 & 86,96 & 23 & 100 \\
\hline 5 & 19 & 86,36 & 6 & 28,57 & 20 & 90.91 & 21 & 91,30 & 21 & 91,30 & 21 & 91,30 \\
\hline 6 & 20 & 90,91 & 18 & 85,71 & 22 & 100 & 21 & 91,30 & 22 & 95,65 & 23 & 100 \\
\hline 7 & 18 & 81,82 & 20 & 95,24 & 20 & 90,91 & 20 & 86,96 & 13 & 56,52 & 19 & 82,61 \\
\hline $\begin{array}{l}\text { Jumlah } \\
\text { siswa yang } \\
\text { hadir }\end{array}$ & & 22 & & 21 & & 22 & & 23 & & 23 & & 23 \\
\hline
\end{tabular}

Keterangan:

1 = Melakukan diskusi dengan anggota kelompok untuk memahami materi yang sedang dipelajari.

2 = Memperhatikan penjelasan ketua kelompok pada saat diskusi kelompok.

3 = Mengajukan atau membuat pertanyaan kepada guru/teman.

4 = Menjawab pertanyaan yang diberikan teman.

5 = Menyampaikan ide terhadap penyelesaian masalah dalam kelompok.

6 = Memperhatikan presentasi yang diberikan teman

7 = Membuat atau melengkapi catatan sendiri 


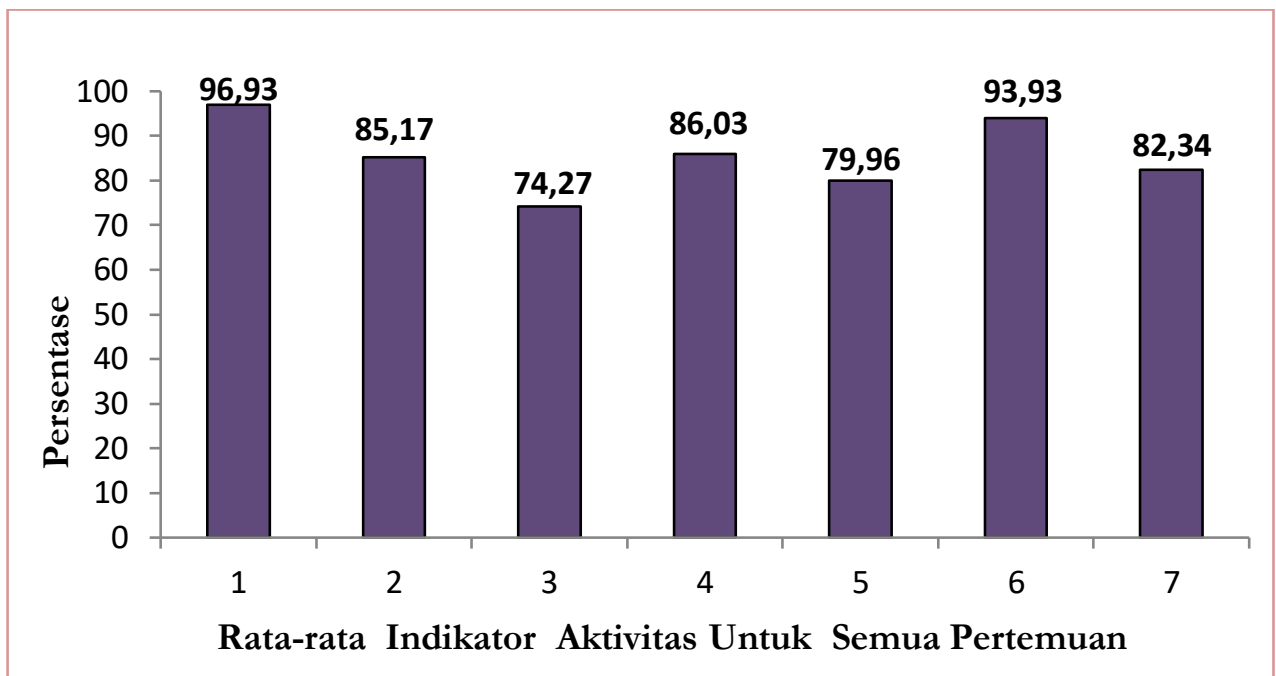

Gambar 1. Diagram Batang Rata-Rata Persentase Aktivitas Siswa untuk Setiap Indikator untuk Semua Pertemuan Selama Penerapan Model Pembelajaran Aktif Tipe Snowball Throwing yang Disertai dengan Peta Konsep Dalam Pembelajaran Matematika

Persentase rata-rata seluruh aktivitas siswa pada setiap pertemuan untuk setiap indikator dapat dilihat pada Gambar 1. Berdasarkan Gambar 1 di atas rata-rata persentase aktivitas siswa yang sangat tinggi terdapat pada aktivitas pertama yakni aktivitas melakukan diskusi dengan anggota kelompok untuk memahami materi yang sedang dipelajari. Sedangkan aktivitas terendah terdapat pada aktivitas yang ketiga yakni aktivitas mengajukan atau membuat pertanyaan kepada guru/teman.

\section{PENUTUP}

Berdasarkan penelitian yang telah dilakukan dapat disimpulkan bahwa aktivitas siswa kelas VIII SMP Negeri 1 Padang Tahun Pelajaran 2011/2012 dalam pembelajaran matematika selama diterapkan pembelajaran aktif tipe Snowball Throwing yang disertai penggunaan peta konsep cenderung mengalami peningkatan. Hal ini dapat dilihat dari siswa yang aktif untuk memahami materi yang mereka pelajari dengan melakukan diskusi melalui peta konsep dan lembar penuntun diskusi yang diberikan guru. Kemudian, setiap kelompok juga berdiskusi membuat soal beserta jawabannya serta melakukan permainan antar kelompok dengan cara setiap kelompok saling bertukar soal dan menjawab soal yang mereka tukarkan tersebut.

\section{UCAPAN TERIMA KASIH}

Terima kasih diucapkan kepada Bapak Drs. H. Yarman, M.Pd. yang memberikan dukungan dan arahan dalam penerapan pembelajaran aktif tipe Snowball Throwing yang disertai penggunaan peta konsep di SMP Negeri 1 Padang.

\section{DAFTAR PUSTAKA}

Dimyati dan Mudjiono. (2002). Belajar dan Pembelajaran, Rineka Cipta, Jakarta.

Silberman, Mel. (2009). Active Learning 101 Strategi Pembelajaran Aktif, Pustaka Insan Madani, Yogyakarta.

Sudjana, Nana. (2009). Penilaian Hasil Proses Belajar Mengajar, Rosdakarya, Bandung. 
Suprijono, Agus. (2010). Cooperative Learning Teori dan Aplikasi

PAIKEM, Pustaka Pelajar, Yogyakarta. 